\title{
ON MANGANESE IN SEA AND FRESH WATERS
}

\author{
By H. W. Harvey, Sc.D., F.R.S.
}

Hydrologist at the Plymouth Laboratory

(Text-figs. I-4)

Chemical and spectrographic analyses have shown that the sea contains a variable quantity of manganese, ranging between $\mathrm{I}$ and $\mathrm{I0} \mathrm{mg}$. $/ \mathrm{m} .^{3}$ (Thompson \& Wilson, I935; Noddack \& Noddack, I940), while river waters contain some 500 to $1000 \mathrm{mg} . / \mathrm{m}^{3}$ (Twenhofel, 1938). These estimates include manganese in solution and that present as particulate or colloidal oxides soluble in concentrated hydrochloric acid.

In the deep waters of the oceans there is a continuous rain of manganese oxides falling on the ocean floor. Pettersson (1945) estimates that some Io mg. of manganese may fall on each square metre annually.

In a previous communication it was shown that the sea off Plymouth contained, in 1946, insufficient manganese for the continued growth of several species of flagellates (Harvey, 1947). The experimental data, considered as a biological estimation of manganese in the water, indicated that the water contained only a fraction of $\mathrm{I} \mathrm{mg.} / \mathrm{m}^{3}$ in a form available to plant life.

These various observations indicate that the state of manganese in the seaionic, colloidal or particulate - and its distribution, are a pertinent subject for inquiry. Manganese is necessary for marine life. Sea waters obtained from different localities and depths are known to differ, the one from the other, in their capacity to support marine plant life irrespective of their content of available nitrogen, phosphorus and iron. It is not known what part, if any, varying concentrations of manganese in an available form may play in affecting the biological environment provided by the sea from place to place.

\section{Estimation of Manganese Soluble in Dilute Acids}

The oxidation of tetramethyldiaminodiphenylmethane (tetrabase) in solutions containing periodate, to form a transient blue compound, is catalysed by traces of manganese. This reaction has been used by Nicholas (1946) to estimate this element in plant tissues. It was found possible to develop the method so that it could be used to estimate manganese in sea water to within a small fraction of a milligram per cubic metre of water.

The oxidation does not allow the estimation of manganese in solution in water at $\mathrm{pH} 8$, since it can only be carried out in dilute acid, the tetrabase being insoluble in neutral solution. It is thought that the concentration of 
manganese in the sea, present both in the ionic form and as colloidal or particulate oxides soluble at $\mathrm{pH}_{4} \cdot 7$, should provide a fair index of the maximum concentration of manganese likely to be available to plants. Any colloidal micelles or particles which dissolve at a $\mathrm{pH}$ one or two units lower than that of natural sea water are likely to be available to plants, as is iron oxide (Harvey, 1937), the $\mathrm{pH}$ at the plant-water interface being lower than in the surrounding water (Danielli, 1944). On the other hand, particles which are insoluble in dilute acid are unlikely to be available, unless conditions at the plant-water interface are tantamount to a reducing medium, for which there is no evidence. (Particles of manganese oxides insoluble in dilute acid are readily soluble in an acidic reducing medium.)

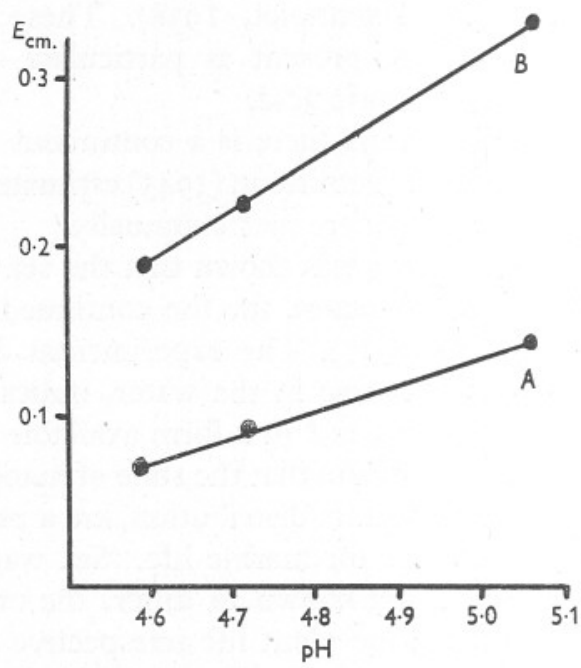

Fig. I. Relation between $\mathrm{pH}$ and the extinction coefficient $(E)$ in yellow light of the transient blue formed in sea water $(A)$ and in the same sea water to which $3 \mathrm{mg}$. $\mathrm{Mn} / \mathrm{m} .^{3}$ had been added $(B)$. Waters buffered with hydrochloric acid and ammonium acetate, and containing $50 \mathrm{mg}$. potassium periodate and $35 \mathrm{mg}$. tetrabase per litre.

When tetrabase is added to a solution containing periodate and manganese ions, oxidized to high valency by the periodate, a blue colour develops and quickly fades. In strongly acid solution the coloured oxidation product is unstable and is not formed. The intensity of blue colour formed depends upon the following factors:

(i) The concentration of tetrabase in solution. This is very insoluble in neutral solution, its solubility increasing with increasing acidity.

(ii) The hydrogen-ion concentration. With increasing acidity and the same concentration of tetrabase, less blue is formed (Fig. I).

(iii) The concentration of periodate present. It was also observed that less blue is formed when using a freshly made solution of periodate than with 
a solution of the same concentration which has aged and started to smell of ozone. Ozone or ozonides play a part either in the oxidation of manganousmanganese or of the tetrabase.

Thus, of the reagents used, the periodate solution becomes more effective on aging, while the solution of tetrabase in acetone becomes less effective.

(iv) The oxidation period, or time during which the periodate has been mixed with the buffered sea water before mixing with tetrabase. Some evidence indicated that the oxidation of manganese ions to higher valency, having catalytic activity, is not quantitative but that an equilibrium mixture of polyvalent states is set up. This equilibrium mixture is unstable in buffered sea water, slowly reverting after an interval of time.

(v) Salts in solution. At the same $\mathrm{pH}$ and with the same concentration of periodate and tetrabase, the increase in blue developed due to unit addition of manganous salt was greater in water than in sea water, or in $3 \frac{1}{2} \%$ sodium chloride solution.

(vi) The nature and quantity of organic solvent in which the tetrabase has been dissolved. The most satisfactory results have been obtained by adding the water and buffer and periodate to tetrabase dissolved in acetone, so that sufficient tetrabase is present to saturate fully the resulting mixture. If an excess of acetone is used, thereby increasing the solvency of the final mixture, no colour develops.

(vii) Manganese present. With solutions of a manganous salt in distilled water, containing up to $3 \mathrm{mg}$. $\mathrm{Mn} / \mathrm{m}^{3}$, and buffered with ammonium acetate and hydrochloric acid, a linear relation was found between the blue developed and the quantity of manganese present. An experiment such as is shown in Fig. 2 allows the 'reagent blank' to be calculated.

With lesser concentrations of tetrabase, the colour developed did not bear a linear relation to the quantity of manganese present, being proportionately less for greater than for smaller additions. From this observation it is concluded that there is a linear relation between the quantity of catalyst and the quantity of tetrabase transformed only when the concentration of the latter is at least 40,000 times that of the catalyst-about I0,000 times more molecules of tetrabase than of the catalytic manganese ions.

With sea water or sodium chloride, buffered at $\mathrm{pH}_{4} \cdot 6$, to which manganese in quantity not exceeding $3 \mathrm{mg} . / \mathrm{m} .^{3}$ had been added, the relation between blue formed and manganese present was not strictly linear with $\mathrm{I} 30 \mathrm{mg}$. $/ 1$. of tetrabase present (Fig. 3). This lack of linearity was found with I30 mg./1. of tetrabase at acidities varying between 4.5 and $5.0 \mathrm{pH}$ and with a wide range of periodate concentrations.

This lack of linearity suggested that the salts in solution in the sea water affected the oxidation of the tetrabase by lowering its effective concentration relative to that of the active manganese. It was possible to increase the concentration of tetrabase to $200 \mathrm{mg}$./1. without causing turbidity by precipitation 
in sea water, and probably to decrease the concentration of active manganese by adding less periodate.

Under these conditions the transient blue formed showed a linear relation to the quantity of added manganese salt (Fig. 4).

The procedure adopted in this experiment was as follows. There were added to 50 c.c. of sea water, from which most of the particulate matter had

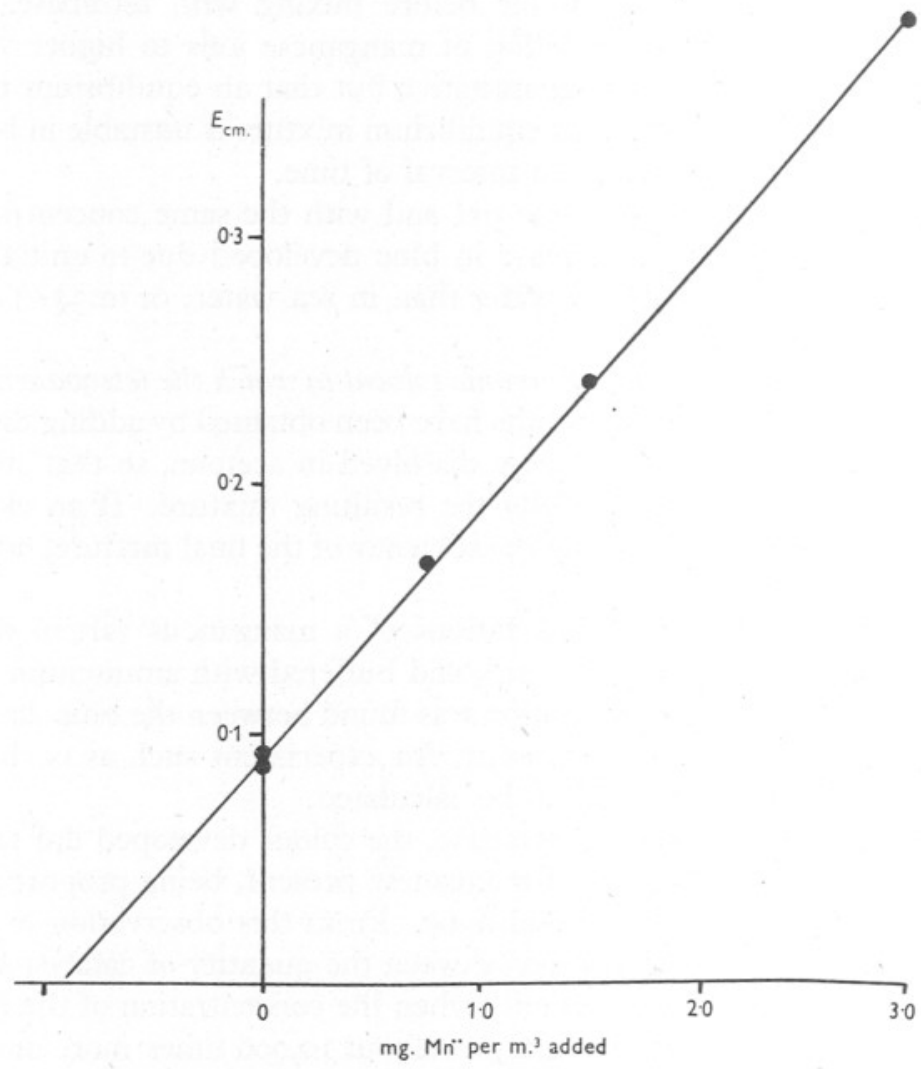

Fig. 2. The relation between the blue colour developed in distilled water, buffered at $\mathrm{pH} 4 \cdot 8$, and the quantity of manganese added. The extinction coefficients are of yellow light passing 'Ilford Spectrum 606' filters. Concentration of tetrabase, I30 mg./1.; of potassium periodate, $30 \mathrm{mg} . / 1$. Reagent blank deduced $=0.9 \mathrm{mg} . \mathrm{Mn} / \mathrm{m}^{3}$

settled during storage in a glass carboy, (i) $1 \cdot 5$ c.c. of hydrochloric acid c. $\mathrm{I} \cdot 75 \mathrm{~N}$, and 3 days later (ii) $\mathrm{I} \cdot 5$ c.c. of a solution of $100 \mathrm{~g}$. ammonium acetate in 200 c.c. of water, and (iii) 3.7 c.c. of a solution containing $0.85 \mathrm{mg}$. potassium periodate (as found by titration in alkaline solution with sodium arsenite after adding potassium iodide). The oxidation of the manganous ions present was allowed to proceed for exactly to min. when the liquid was poured quickly into 4.5 c.c. of a $0.25 \%$ solution of tetrabase in acetone 


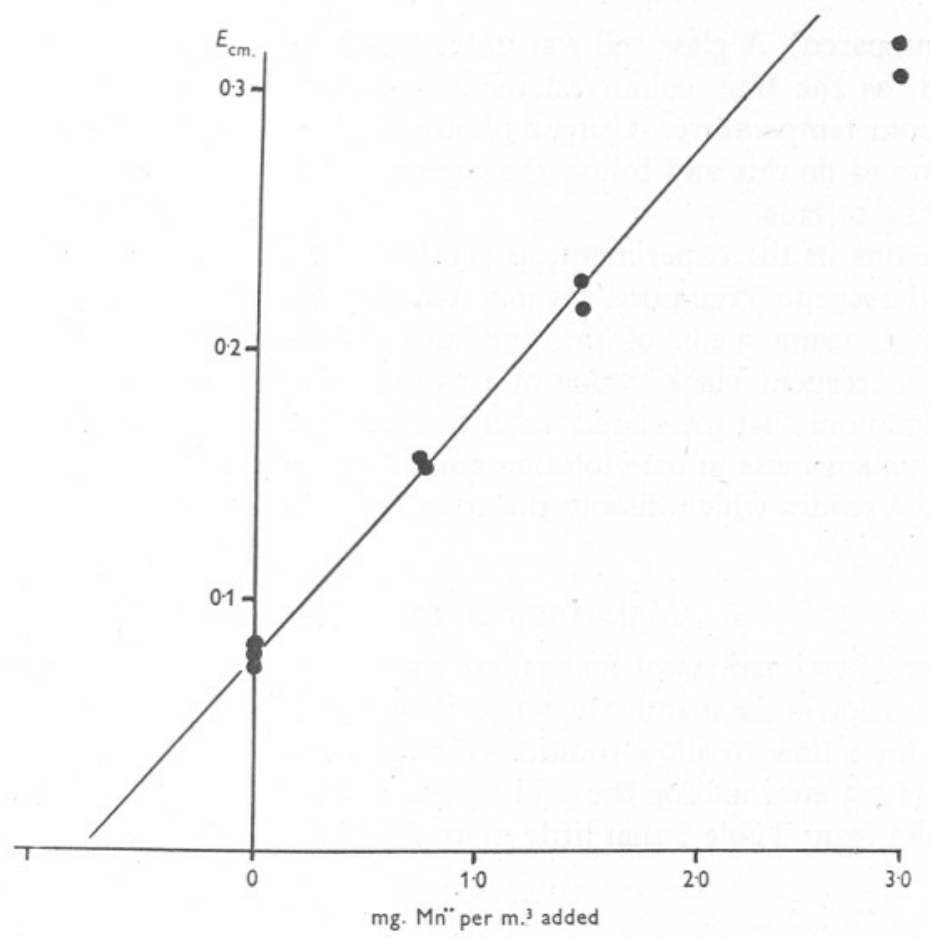

Fig. 3. Relation between colour formed and quantity of manganous salt added to sea water buffered at $\mathrm{pH} 4 \cdot 6$. Concentration of tetrabase, $130 \mathrm{mg} . / 1$; of potassium periodate, $42 \mathrm{mg} . / 1$.

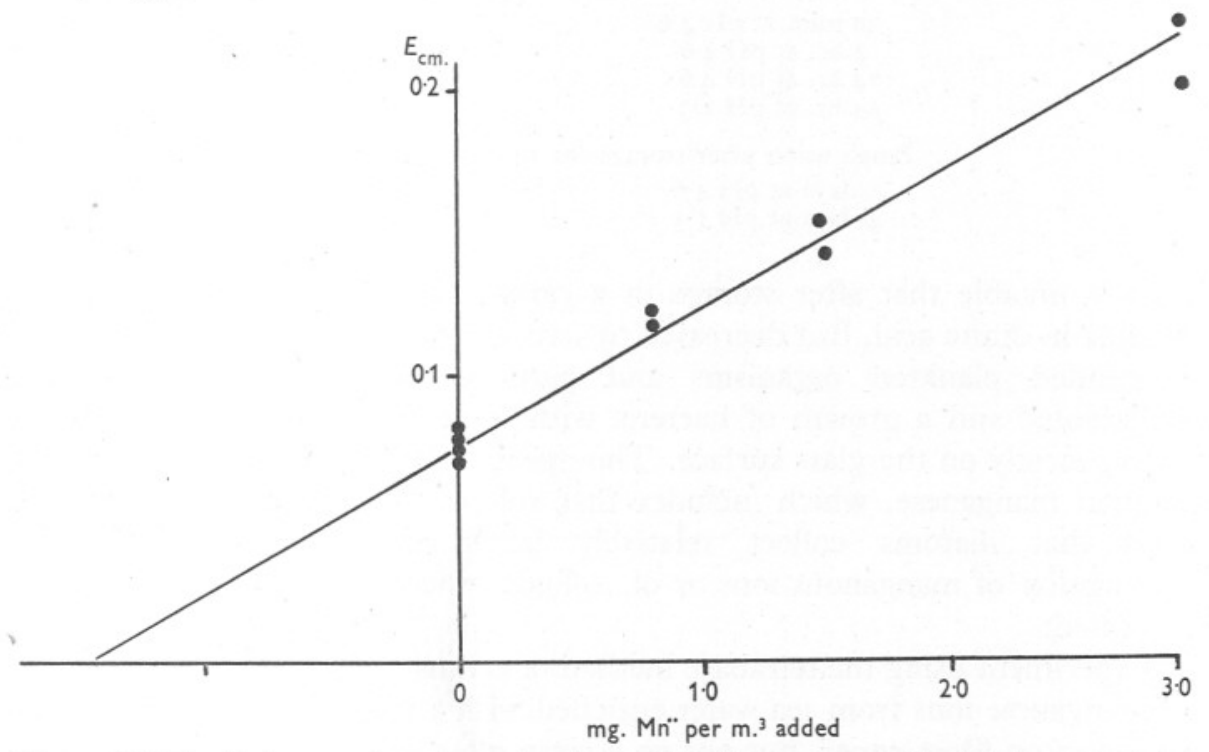

Fig. 4. Relation between colour formed and quantity of manganese salt added to stored sea water. Concentration of tetrabase, $200 \mathrm{mg}$./1.; of potassium periodate, I4 mg./1. 
(freshly prepared). A glass cell was immediately filled and its optical density measured, as the blue colour attained its maximum some $40 \mathrm{sec}$. later at winter room temperature. Using a photoelectric absorption meter there was ample time to do this and follow the colour attaining its maximum, pausing and starting to fade.

The results of the experiment, as plotted in Fig. 4, indicate that the sea water and reagents contained $\mathrm{I} \cdot 5 \mathrm{mg} . \mathrm{Mn} / \mathrm{m} .{ }^{3}$ Similar procedure with distilled water, using 3 c.c. of the tetrabase solution and the same buffers, provided a 'reagent blank' value of $\mathrm{r} \cdot 25 \mathrm{mg}$. $\mathrm{Mn} / \mathrm{m}^{3}$. It is concluded from these estimations that the stored water contained $0.25 \mathrm{mg} . \mathrm{Mn} / \mathrm{m} .{ }^{3}$, originally present as manganese in true solution and as any colloidal or minute particles of hydrated oxides which dissolved during the 3 days at $\mathrm{pH} \mathrm{r} \cdot 3$.

\section{MANGANESE IN Sea WaTER}

A number of estimations of manganese in sea water collected off Plymouth have been made in the manner just described. The waters were either buffered and kept for a time to allow solution of manganese oxides at $\mathrm{pH} 4 \cdot 6-4 \cdot 75$ or kept at $\mathrm{pH} \mathrm{I} \cdot 3$ after adding the acid before adding the acetate.

It is seen from Table I that little more dissolves at $\mathrm{pH} \mathrm{I} \cdot 3$ than at $\mathrm{pH} 4 \cdot 6$.

\section{TABLE I}
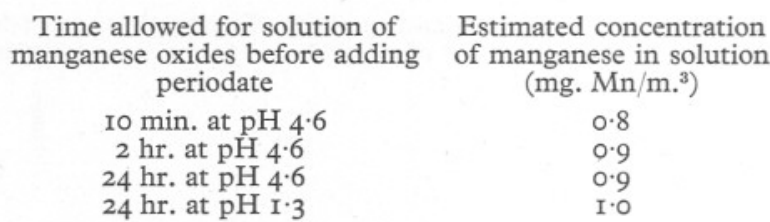

Same water after storage for I4 days in a carboy $\begin{array}{ll}4 \text { days at } \mathrm{pH}_{4} \cdot 6 & 0.0 \\ 4 \text { days at } \mathrm{pH} \mathrm{I} \cdot 3 & 0.2\end{array}$

It is notable that after storage in a carboy for I4 days the manganese, soluble in dilute acid, had decreased to a very low value. During this period, suspended plankton organisms and particles of organic detritus had sedimented and a growth of bacteria with some neritic diatoms had taken place, mostly on the glass surface. Thompson \& Wilson's (1935) estimations of total manganese, which includes that soluble in hot concentrated acid, show that diatoms collect relatively large quantities of manganese. Adsorption of manganous ions or of colloidal micelles of hydrated oxides is indicated.

Experiment using the tetrabase method of estimation has shown adsorption of manganese ions from sea water enriched with a manganous salt on protein and even on filter-paper, but not on a clean glass surface. 
The deposition of colloidal iron hydroxide on aquatic plants is a common phenomenon. Presumably colloidal and minute particles of oxide of manganese will tend to deposit on organisms in a similar manner.

The next series of estimations show a similar decrease in concentration of soluble manganese after 8 days' storage in a bottle, and further indicate that the adsorbed fraction is wholly eluted by acid at $\mathrm{pH} \mathrm{r} \cdot 3$.

\section{Table II. Sea Water Collected from a Depth of 2 M. about 8 Miles OfF Plymouth, 5 April 1948}

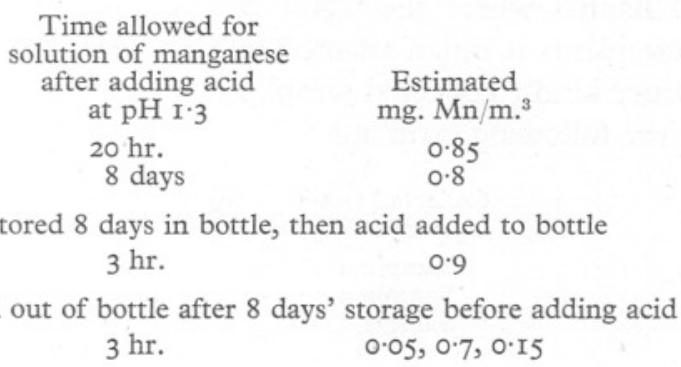

In subsequent estimations a buffer mixture was used, consisting of: II 7 c.c. glacial acetic acid, 56 c.c. concentrated hydrochloric acid, II3 c.c. 0.880 ammonium hydroxide, 490 c.c. distilled water; and 3 c.c. were added to 50 c.c. of water.

This buffered sea water gave a lower 'reagent blank' value than the ammonium acetate mixture used previously.

In order to determine whether there was any marked difference in concentration of soluble manganese with depth of the water, the series of estimations shown in Table III was made.

\section{Table III. Water Collected 20 Miles Seaward from Plymouth ON 8 JUNE I948, DEPTH $72 \mathrm{M}$.}

$\begin{array}{ccc}\begin{array}{c}\text { Sample from } \\ \text { (m.) }\end{array} & \begin{array}{c}\text { Time allowed for solution } \\ \text { of manganese after } \\ \text { adding buffer at } \mathrm{pH} 4.76\end{array} & \begin{array}{c}\text { Estimated } \\ \mathrm{mg} . \mathrm{Mn} / \mathrm{m}\end{array} \\ 0.5 & 30 \mathrm{~min} . & \mathrm{I} \cdot \mathrm{I} \\ 5 & & 0.9 \\ 25 & & \mathrm{I} \cdot 0 \\ 50 & \mathrm{I} \cdot \mathrm{I} \\ 70 & \mathrm{I} \cdot \mathrm{I} \\ \text { Water collected from same position 30 June I948 } \\ 5\end{array}$

Water collected $50^{\circ} 00^{\prime} \mathrm{N} .7^{\circ} 10^{\prime}$ W., 30 June 1948 , depth Iro m.
75
$20 \mathrm{hr}$.
0.45
$0 \cdot 25,0 \cdot 3$ 
The water occupying the area off Plymouth on 30 June contained less soluble manganese than samples collected earlier in the year. This water differed in other characteristics from that collected in the area during the previous and subsequent months, and in common with the water collected from $7^{\circ} \mathrm{IO} \mathrm{O}^{\prime} \mathrm{W}$. it contained a considerably larger quantity of organic phosphorus.

I am indebted to Dr M. Parke for the information that the waters of Port Erin Bay, in the Isle of Man, usually contain a rich flora of flagellates during the summer months. In consequence, it was interesting to find whether these waters were richer in soluble manganese than those sampled in the mouth of the English Channel where the water contains fewer flagellates, since the growth of these plants is much affected by shortage of available manganese.

Mr J. R. Bruce kindly collected samples from the former locality, which on analysis gave the following estimates:

$\begin{array}{cc}\text { Collected from } & \text { mg. Mn } / \mathrm{m}^{3} \text { after } \\ \text { Port Erin Bay } & 24 \mathrm{hr} \text {. at } \mathrm{pH} 4 \cdot 7 \\ \text { Sample } a & 2 \cdot 2 \\ \text { Sample } b & 2 \cdot 6 \\ \text { Sample } c & 2 \cdot 0\end{array}$

In this usually flagellate-rich locality the water contained more than twice as much soluble manganese as the waters sampled in the English Channel.

\section{MANGANeSE IN Fresh Waters}

River waters are known to contain relatively large quantities of manganese. Twenhofel (1938) writes of $500-5000 \mathrm{mg} . / \mathrm{m}^{3}$ in streams, 'in which it is probable that the prevalent method of transportation of manganese is as oxide hydrosols stabilized by organic colloids'.

It was of interest to find how much of this total was in the form of manganese soluble in dilute acid, and how this varied with the nature of the stream.

Samples of natural waters were collected in June I948, those from the Lake District by Mr F. J. Mackereth who also kindly supplied the appended particulars relating to the usual planktonic life in the six waters. The results of examining these samples are given in Table IV.

It is noteworthy that the readily acid-soluble manganese varies in the waters from the Lake District in roughly the same order as their productivity. It seems improbable that the manganese content in any way controls the productivity, but more likely that it is affected by those factors which themselves control plant and animal growth. Heintze \& Mann (1946) find that more manganese can be washed out from agricultural soils containing greater quantities of organic matter than from soils containing less organic matter. Moreover, addition of organic compounds to the water increased the manganese in the leachate. 


\section{Table IV. Manganese in Samples of River and Lake Water}

Devonshire:

\section{Locality}

River Yealm at Wisdome on leaving moorland

River Yealm at Yealm Bridge after passing through some 7 miles of agricultural country

Plymouth tap water (moorland reservoir)

Lake District:

Esthwaite. 'A very productive lake' surrounded by agricultural land

Bellham Tarn. 'A small lake containing a good supply of nutrients but not so productive as Esthwaite'

Black Beck. Stream feeding Esthwaite and bringing in most of the nutrients

Windermere (North Basin). Of fairly high productivity for diatoms, but few blue-green algae

Loweswater. A lowland lake lying in agricultural land and usually fairly productive

Ennerdale. Usually very poor in planktonic organisms and has low concentrations of nutrients mg. $\mathrm{Mn} / \mathrm{m}^{3}$ soluble

after 24 hr. at $\mathrm{pH}_{4} \cdot 7$

$$
\begin{aligned}
& I \cdot 15 \\
& \text { IO } \\
& \text { I } \cdot 8 \\
& >40 \\
& 20 \\
& \text { I2 } \\
& \text { IO } \\
& \text { II } \\
& \text { (after } 44 \mathrm{hr} \text {. II, 7.5) } \\
& 6.5,8
\end{aligned}
$$

(after 44 hr. $8,8 \cdot 5$ )

\section{SUMMARY}

A method of estimating the maximum quantity of manganese available to plants in sea and fresh waters is described.

Samples of sea water collected off Plymouth in 1948 contained 0.7-I.0 mg. $\mathrm{Mn} / \mathrm{m}^{3}$ in solution plus any particles soluble at $\mathrm{pH} 4 \cdot 6$. After storage and sedimentation of particulate matter, the quantity decreased to $0 \cdot 0-0.25 \mathrm{mg} . / \mathrm{m}^{3}$

Samples collected off the Isle of Man, an area with a rich summer population of flagellates, contained $2 \cdot 0-2 \cdot 6 \mathrm{mg} . / \mathrm{m}^{3}$

The river Yealm, south Devon, on leaving Dartmoor contained I mg., and after passing through agricultural land Io $\mathrm{mg} . / \mathrm{m} .^{3}$

Lakes and streams in the English Lake District contained $6-40 \mathrm{mg} . / \mathrm{m} .{ }^{3}$ The least fertile waters contained the least soluble manganese. 


\section{REFERENCES}

DANIELLI, J. F., I944. The biological action of ions and the concentration of ions at surfaces. Fourn. Exp. Biol., Vol. 20, pp. 167-76.

Harvey, H. W., I937. The supply of iron to diatoms. Fourn. Mar. Biol. Assoc., Vol. 22, pp. 205-I9.

I947. Manganese and the growth of phytoplankton. Fourn. Mar. Biol. Assoc., Vol. 26, pp. 562-79.

Heintze, S. G. \& MANN, P. J., I946. Divalent manganese in soil extracts. Nature, Vol. I58, p. 79I.

NicholAs, D. J., I946. Detection of manganese deficiency in plants by tissue tests, using tetramethyldiaminodiphenylmethane. Nature, Vol. 157, p. 695.

NoDDAck, I. \& NodDack, W., I940. Die Häufigkeiten der Schwermetalle in Meerestieren. Arch. Zool., Bd. 32, No. I, p. I.

Pettersson, H., I945. Iron and manganese on the ocean floor. Göteborgs Kungl. Vetensk. Vitterh. Sam. Handl., Ser. B, Bd. 3, No. 8, 37 pp.

Thompson, T. G. \& Wilson, T., I935. The occurrence and determination of manganese in sea water. Fourn. Amer. Chem. Soc., Vol. LvIr, pp. 233-6.

Twenhofel, W. H., I938. Principles of Sedimentation. New York and London. 